\title{
Improvement of the System of Training of Specialists by University for Coal Mining Enterprises
}

\author{
Vadim Mikhalchenko ${ }^{1, *}$, and Irina Seredkina ${ }^{1}$ \\ ${ }^{1}$ T.F. Gorbachev Kuzbass State Technical University, Department of Economics, \\ Vesennaya str., 28, Kemerovo, Russia, 650000
}

\begin{abstract}
In the article the ingenious technique of the Quality Function Deployment with reference to the process of training of specialists with higher education by university is considered. The method is based on the step-by-step conversion of customer requirements into specific organizational, meaningful and functional transformations of the technological process of the university. A fully deployed quality function includes four stages of tracking customer requirements while creating a product: product planning and design, process design, production design. The Quality Function Deployment can be considered as one of the methods for optimizing the technological processes of training of specialists with higher education in the current economic conditions. Implemented at the initial stages of the life cycle of the technological process, it ensures not only the high quality of the "product" of graduate school, but also the fullest possible satisfaction of consumer's requests and expectations.
\end{abstract}

\section{Introduction}

The modern development of the world economy demonstrates an increasingly growing competition, the quickening pace of changes and innovations based on the latest achievements of scientific and technological progress, which are inherently continuing in nature. The demand for new, the most sophisticated products is met with increasing speed. At the same time, consumer, showing selectivity, special preferences and expectations, insistence to the standard of goods or services provided, has become a key factor for the modern business success [12]. As noted by W. Scherkenbach, one of the Chief of "Ford" company, "The business process starts with the consumer. If the business was not started with the consumer - it will end with the consumer!'[11].

Strong manufacturers are crowding out the weaker one by offering products of higher quality at the best price and with better service to customers. At the same time, consumers may not be particularly retained even by those suppliers that fully comply with their level of requests. In the face of increasing competition, there is always a chance to get something that can be even better.

\footnotetext{
*Corresponding author: V.Mikhalchenko@mail.ru
} 
Thus, the strongest positions in the market are received by those producers who have more complete knowledge about the consumer and, ahead of his expectations, continuously improve their production, managerial and social systems, thereby creating competitive advantages for themselves and ensuring long-term stability of their business. At the same time, the level of employees' professional qualification is one of the most important key factors in achieving success and strategic goals of the organization's development.

Under these conditions, in the system of relations with the labor market, the university should position itself not only as a "forge of staff", as a supplier of highly skilled human resources, but also as an active business partner what continuously "improves" its product and ensures full compliance with the level of training of young professionals according to the current and prospective needs of employers.

At the same time, as the results of a sociological survey showed, the employer, for example, a large coal mining company of the Kuznetsk Coal Basin of the Russian Federation, is not satisfied with the quality of training of specialists with higher education by universities. The consumer of the products of higher education institutions does not receive on a permanent basis that "product" that would fully correspond to its ideas about the high level of training of specialists in many aspects of quality which is necessary for the implementation of the organization's strategic goals. At the same time, in the "universityenterprise" system, there is often no direct interaction between the parties to solve the problems of the quality of training of specialists. On the one hand, the employer is not burdened with obligations, not interested and does not consider it necessary to notify universities about what they should pay attention to when forming the required qualities in the process of training of specialists with higher education; on the other hand, universities practically do not make research and do not take into account the needs and requests of real consumers of their products, and in the process of developing their curriculam and work programs rely, to a greater extent, on the compliance of the latest requirements of state educational standards and their capabilities [1].

In this regard, the task of building a system, within which the customer's requirements will be converted into the quality parameters of the product expected by him and, accordingly, into the quality parameters of the training of young specialists by the university, is particularly relevant. At the same time, this system should be able to react flexibly to rapid changes in the business environment, literally "pulling the requirements to the product" from the consumer and reconfiguring the labor, material resources and technological process of training of specialists according to the changing trends of the external environment, which fully corresponds to the most effective and recognized in world practice approaches in building production systems in modern economic conditions and, in particular, to the principles and concept of lean-production [13] and "active" (agile manufacturing) [6] production.

\section{Theory}

One of the effective tools that has been distributed in recent years and used by many successful manufacturing companies in the world in addressing the above issues is the Quality Function Deployment method [7, 9].

This method was used in 1972 in Mitsubishi Company for the first time, and since 1977 is actively used in Toyota production system (TPS). It is based on the step-by-step conversion of customer requirements ("consumer votes") into specific engineering, technological specifications of the product, organizational, functional and other components of the company itself.

Within the framework of this method, it is necessary to answer the question "How to do it?" in order to implement the list of customer wishes ("What to do?"). In other words, to 
deploy the quality function means to identify a set of technological parameters, factors and production conditions that radically determine the result (product) of productive activity in such a way as to satisfy the consumer completely.

It is possible to avoid (or at least minimize) adjusting the quality of the product after its appearance on the market by deploying quality at the initial stages of the product life cycle in accordance with the consumer's needs and wishes, and therefore to provide high value and at the same time a relatively low cost product (by minimizing the costs of repairing the spoilage) [2]. The methodology of the Quality Function Deployment has shown its high efficiency for companies operating in a volatile and highly competitive external environment and, of course, can be successfully applied to the conditions of the educational process.

\section{Discussion}

The product of a university is a specialist with the necessary knowledge to ensure the realization of the company's goals. The process of training of specialist passes through certain stages and can be considered as a technological process with a certain set of technological parameters, conditions, functions. It is possible to get a product that fully meets the employer's needs by managing these components, constructing a meaningful set of elements of the studying process. This task is especially relevant for the companies operating in the field of knowledge. Currently the conversion rate is so high that, according to some statements, total amount of knowledge doubles on average over ten years (at the time of Lomonosov over 150 years), and 30\% of knowledge obtained in university becomes obsolete immediately after graduation. In this regard, it is necessary to make changes continuously in the educational process and constantly "be in touch" with the consumer.

The present study proposes to use the following algorithm for improving the system of training of specialists with higher education by university.

At the first stage of the Quality Function Development ("market research"), the team of experts (the quality management team from the university) should identify key consumers and, with the help of selected methods (survey, analysis of statements in the media, complaints, etc.) formulate and systematize their main requirements ("consumer voice") to the quality of training of specialists with higher education. There is a "pulling" of the value of the product that is required by the consumer at the moment. As an example of such work, one can cite the "quality profile" of training of specialists with higher education for the enterprises of the coal mining complex, formed as a result of an earlier sociological study [1]. With the further deployment of the quality function from the whole variety of obtained quality parameters it is necessary to select the most important for the consumer. The rating of the quality parameters can be generated using the results obtained during the application of the Kano model [3, 4], ABC method, construction of the Pareto diagram [10]. The most important quality parameters are assigned the highest score of the rating, the least important quality parameters - the lowest score.

At the same time, a comparative assessment of university is conducted with its main competitors relative to the level of implementation of the identified quality parameters. This work is necessary to clarify the situation according to which consumer requirements the position of the university is strong and it is not required to spend time and resources on their satisfaction at this stage.

In further work on the deployment of the quality function, it is necessary to establish how much the supporting processes affect the level of implementation of the quality parameters. Evaluation of the communication tightness can be based on the experts experience, consumer responses or results of specially conducted experiments. The technical part of this work is the construction of the "product design" matrix (Figure 1) [8]. 
Figure 1. Product Design Matrix.

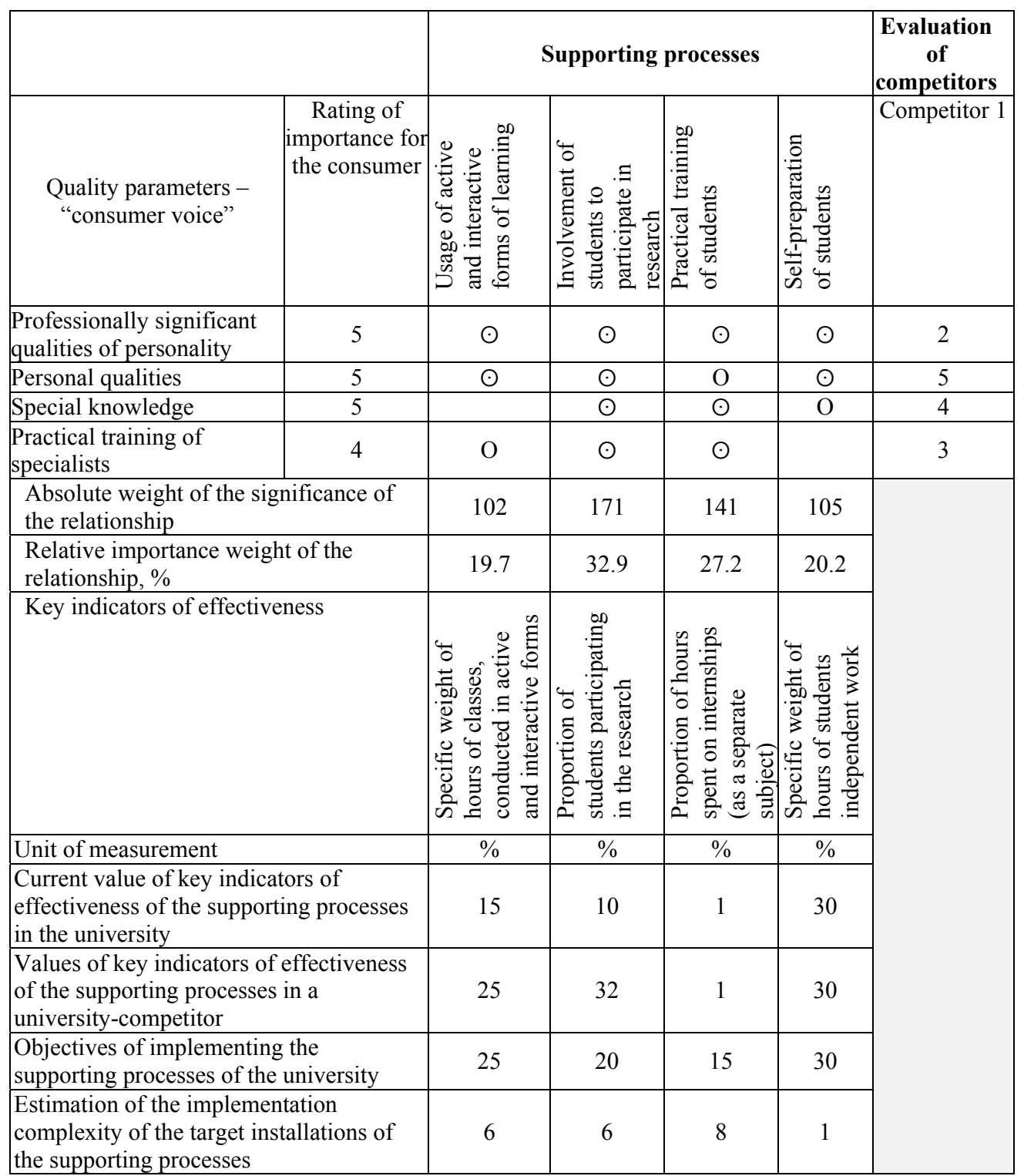

$\odot$ - strong - 9 points, $\mathrm{O}$ - average -3 points, $\Delta$ - weak -1 point

In the future, the most critical (priority) processes are selected from the whole variety of processes which ensure the realization of quality parameters. It is achieved by calculating the indicator of the "significance of the relationship" and the choice of processes with the highest significance of the relationship value:

$$
Z=\sum_{i=1}^{n} \text { strength of relationship } \times \text { customer rating of quality parameters }
$$


In the shown example, the involvement of students to participate in research and practical training of students are the university processes that highly influence on the quality formation of specialists with higher education which are valuable for the employer.

From the example (Figure 2), it can be seen that improving the process of practical training of students may require the development of basic educational programs in terms of planning students' training at real workplaces in conditions of real corporate life, methodological and consulting support for such training by faculty, building relations with companies in order to organize on their basis a long-term internship and thereby provide students with the training which meets current industry standards.

At the next stage - "production design" - tasks, rules, procedures, instructions, assignment are formulated, job descriptions, regulations of educational, administrative and other processes of the university are developed, equipment, mode of operation, methodological materials, quality control tools are selected.

Figure 2. Process Design Matrix.

\begin{tabular}{|c|c|c|c|c|c|c|}
\hline & \multicolumn{4}{|c|}{ Supporting processes } & \multirow{2}{*}{$\begin{array}{c}\begin{array}{c}\text { Evaluation } \\
\text { of } \\
\text { competitors }\end{array} \\
\text { Competitor } 1\end{array}$} \\
\hline Supporting processes & $\begin{array}{l}\text { Rating of } \\
\text { quality } \\
\text { parameters }\end{array}$ & 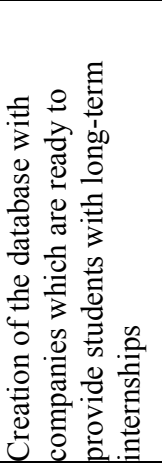 & 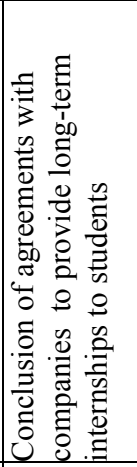 & 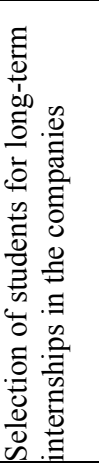 & 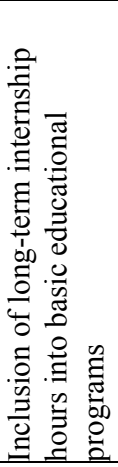 & \\
\hline $\begin{array}{l}\text { Practical training of } \\
\text { specialists }\end{array}$ & 0.272 & $\mathrm{O}$ & $\odot$ & $\mathrm{O}$ & $\odot$ & 3 \\
\hline \multicolumn{2}{|l|}{ Values of relationship } & 0.816 & 2.448 & 0.816 & 2.448 & \\
\hline \multicolumn{2}{|l|}{ Parameters of subprocess } & 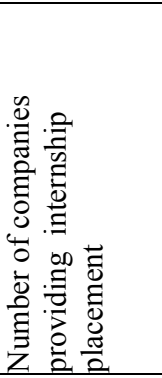 & 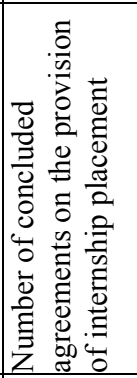 & 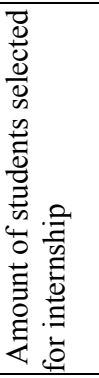 & 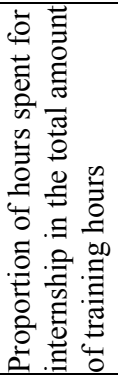 & \\
\hline \multicolumn{2}{|l|}{ Unit of measurement } & unit & unit & unit & $\%$ & \\
\hline \multicolumn{2}{|c|}{$\begin{array}{l}\text { Current value of sub process } \\
\text { parameters }\end{array}$} & 270 & 10 & 1 & 1 & \\
\hline \multicolumn{2}{|c|}{$\begin{array}{l}\text { Objectives for implementing sub } \\
\text { processes }\end{array}$} & 400 & 100 & 30 & 3 & \\
\hline \multicolumn{2}{|c|}{$\begin{array}{l}\text { Complexity level of implementing } \\
\text { target installations of sub processes }\end{array}$} & 4 & 5 & 7 & 7 & \\
\hline
\end{tabular}




\section{Conclusion}

Conversion of the customer requirements and expectations into specific parameters and characteristics of the "product" of higher education through continuous organizational and functional transformation of the university itself is a relevant task of the modern period of world economy development.

An effective tool for solving this problem is "Quality Function Deployment" method, which, in the context of continuous changes in the parameters of the external environment, allows not only "to extract value" from the consumer, but also to determine the directions for improving the technological process of creating the product required by the consumer, and includes four stages: "product planning", "product design", "process design", "production design".

Success in improving the system of training of specialists with higher education for coal mining enterprises and various sectors of the economy depends to a large extent on how in the university:

- all its functions will be interacted;

- communications are organized between participants in the technological process of training of specialists;

- organizational management system of the university is built;

- system of staff motivation has been formed,

- technology of knowledge transfer will be developed and improved.

The efficiency and competitiveness of the university in the current economic conditions will depend on how effectively the university is able to solve the examined problem.

\section{References}

1. V. Mikhalchenko, I. Seredkina, E3S Web Conf.15, 04005 (2017)

2. AkaoYoji, Ohfuji Tadashi, Naoi, Tomoyoshi, Survey and Reviews on Quality Function Deployment in Japan, (Tokio, JHHG, 1987)

3. N. Kano, Guide to TQM in Service Industries (Beijing, Asian Productivity Org, 1996)

4. J. Moorman, Proceedings, 882 (2012)

5. J.R. Evans, Total Quality Management, Organization, and Strategy 4th edition (SouthWestern, part of the Thomson Corporation, 2012)

6. P.M. Noaker, Manufacturing Engineering, 113, 40 (1994)

7. L .P.Sullivan, Quality Function Deployment, 2, 39 (1986)

8. J. Marsh, The Continuous Improvement Toolkit (B.T. Batsford LTD, London, 1998)

9. James L. Brossert, Quality Function Deployment (Milwaukee, WI: ASQ Quality Press, 1990)

10. R. Koch, The 80/20 Principle: The Secret of Achieving More with Less (London, Nicholas Brealey Publishing, 1998)

11. H. R Neave, The Deming Dimension (London, Willey, 2016)

12. Kenichi Ohmae, The Mind of the Strategist the Art of Japanese Business (Tokio, JHHG, 2015)

13. J.P. Womack and D.T. Jones Lean Thinking. Banish Waste and Create Wealth in Your Corporation (New York, Free Press, 2003) 